$\mathrm{XX}$ Міжнародний симпозіум «Методи дискретних особливостей в задачах математичної фізики/Discrete Singularities Methods in Mathematical Physics»,

УДК 51-74:536.7

MSC 80A05

\title{
Modeling of thermal installations based on thermodynamic approaches \\ ${ }^{1}$ V. Voloshchuk, ${ }^{2}$ Eu. Nikiforovich \\ ${ }^{1}$ National Technical University of Ukraine "Igor Sikorsky Kyiv Polytechnic Institute", Kyiv, Ukraine \\ E-mail:vl.volodya@gmail.com \\ ${ }^{2}$ Institute of Hydromechanics National Academy of Sciences of Ukraine, Kyiv, Ukraine E-mail:eugnik@gmail.com
}

The most widespread approaches to the study of thermal systems involve the itera-tive implementation of the following steps: thermodynamics, heat and mass trans-fer, hydrodynamics, economics and ecology. Such methodology cannot combine economic, environmental and thermodynamic aspects from the beginning of the analysis. It does not provide information concerning not only external, but also in-ternal, caused by thermodynamic inefficiencies of system components, impact fac-tors on economic and ecological characteristics. Modeling methods based on the combined application of the First and Second Laws of Thermodynamics (methods of entropy and exergetic analysis), and their combination with economic and envi-ronmental assessment make it possible to identify the location, magnitude, causes, costs and environmental impact of thermodynamic inefficiencies in an energy con-version system. The paper proposes the improvement of methods for modeling thermal systems on the base of exergy analysis. It has been shown that combining exergetic, economic and ecological assessment can significantly simplify tasks of finding parameters and structure of the studied system. Examples of implementation of such studies have been presented.

Key words: modeling, thermal installation, exergetic analysis.

\section{Моделювання об’єктів теплоенергетики методами термодинамічного аналізу ${ }^{1}$ В.А. Волощук, ${ }^{2}$ С.І. Никифорович \\ ${ }^{1}$ Національний технічний університет України «Київський політехнічний інститут імені Ігоря Сікорського», Київ, Україна E-mail: vl.volodya@gmail.com \\ ${ }^{2}$ Інституті гідромеханіки НАН України, Київ, Україна E-mail: eugnik@gmail.com}

\begin{abstract}
Найбільш поширені підходи до дослідження обєктів теплоенергетики передбачають багаторазову реалізацію таких послідовних кроків розрахунку, як термодинаміка, тепломасообмін, гідрогазодинаміка, економіка та екологія, та не в змозі оцінити й поєднати економічні, екологічні та термодинамічні положення з самого початку аналізу, з'ясувати не тільки зовнішні, але і внутрішні, зумовлені термодинамічною недосконалістю елементів системи, фактори впливу на економічні та екологічні характеристики. Методи моделювання та досліджень, які грунтуються на сумісному застосуванні Першого та Другого законів термодинаміки (методи ентропійного та ексергетичного аналізу), та їх поєднання із економічним та екологічним оцінюванням дають можливість визначити місце, значення, джерела, вартість і негативний вплив на довкілля термодинамічних втрат у процесах передачі та перетворення енергії.
\end{abstract}

(с) Волощук В.А., Никифорович Є.І., 2021 


\begin{abstract}
У роботі запропоновано удосконалення методів моделювання об'єктів теплоенергетики із застосуванням ексергетичного аналізу. Показано, що вирішення задач обгрунтування параметрів та структури до-сліджуваних об'єктів шляхом поєднання ексергетичного, економічного та екологічного методів оцінювання суттєво спрощується. Наведено приклади реалізації такого моделювання.
\end{abstract}

Ключові слова: моделювання, теплоенергетичний об'єкт, ексергетичний аналіз.

\title{
1. Вступ
}

При створенні та експлуатації теплоенергетичної системи виникає потреба вирішувати задачі обгрунтування параметрів або структури системи у заданих умовах.

Математична постановка таких задач в загальному вигляді записується таким чином $[1,2]$

$$
\begin{aligned}
& \underset{X}{\operatorname{minimize}} f(X), \\
& \text { при } X=(V, W, Z),
\end{aligned}
$$

де $V$ - вектор незалежних експлуатаційних параметрів системи (потужність компонентів, масова витрата, тиск, температура робочих тіл тощо); $W$ - вектор незалежних проектних параметрів системи (номінальна потужність компонентів, масова витрата, тиск, температура робочих тіл тощо); $Z$ - вектор незалежних параметрів структури системи; та обмеженнями

$$
\begin{array}{ll}
h_{i}(X)=0, & i=1,2, \ldots, m ; \\
g_{j}(X) \leq 0, & j=1,2, \ldots, m .
\end{array}
$$

Для розв'язку таких задач застосовуються різні методи математичного програмування. Ефективність оптимізаційних методів визначається пошуком найкращого варіанту системи без безпосередньої числової перевірки всіх можливих варіантів. Це забезпечується широким застосуванням досягнень в області математики шляхом реалізації за допомогою комп'ютерних програм ітеративних розрахункових схем, що використовують обгрунтовані логічні процедури та алгоритми. При цьому передбачається багаторазова реалізація таких послідовних кроків розрахунку як термодинаміка, тепломасоообмін, гідрогазодинаміка, економіка та екологія. Для прийнятих початкових значень параметрів системи визначаються іiї характеристики та критерії вибору рішень. Потім, на основі відповідних методів, здійснюється покрокове наближення до кращого рішення (часто формально це $\epsilon$ оптимальне рішення). Такий алгоритм є досить громіздким, який не забезпечує визначення тих етапів передачі та перетворення енергії, де в найбільшій мірі знижується енергоефективність та зростає вартість енергоносія [3]. Наприклад, з позицій існуючого енергетичного підходу ККД ефективності використання енергії палива у сучасному котлоагрегаті знаходиться на рівні $80 \ldots 95 \%$. Згідно такого підходу втрати енергії (а це $15 . .20$ \%) складаються із: втрат теплоти із відхідними газами, від хімічної неповноти згорання, від механічної неповноти згорання, через обмурівку та втрат теплоти із фізичною теплотою шлаків. При такому підході немає кількісного оцінювання найбільш цінних втрат. Зрозуміло, що одна і та ж кількість втраченої енергії від хімічної неповноти згорання та через обмурівку не $\epsilon$ рівноцінними. Адже догорання горючих газів $\left(\mathrm{CO}, \mathrm{H}_{2}, \mathrm{CH}_{4}\right.$, тощо) може забезпечи- 
XX Міжнародний симпозіум «Методи дискретних особливостей в задачах математичної фізики/Discrete Singularities Methods in Mathematical Physics», МДОЗМФ/DSMМPh-2021

ти отримання продуктів згорання з набагато вищим енергетичним потенціалом ніж та ж сама кількість енергії, що виходить за межі установки через обмурівку котла.

В теперішній час у сфері теплозабезпечення будівель пропонується використання конденсаційних котлів як енергоефективного джерела теплоти для систем опалення, оскільки ККД таких котлів, визначених на основі енергетичного балансу по відношенню до вищої теплоти згоряння, знаходиться на рівні 94...96\%. Разом 3 тим, якщо прийняти до уваги, що такі котли забезпечують подачу теплової енергії до споживача 3 температурою $20{ }^{\circ} \mathrm{C}$ (нормована температура повітря в більшості приміщеннях), то можна зрозуміти, що в даному випадку потенціал (придатність для використання) енергії первинного палива (природного газу) 3 температурою згоряння $2000{ }^{\circ} \mathrm{C}$ практично повністю втрачається в процесах іiї трансформації та підводу до споживача. Саме ця термодинамічна недосконалість і повинна бути врахована у характеристиках котлоагрегатів.

Існуючі в науковій та особливо в інженерній практиці показники сумарно враховують вплив різних факторів на енергетичну ефективність установок без можливості роздільного оцінювання впливу кожної необоротності реальних процесів. Саме необоротності є причинами неефективного використання вхідного енергоносія. Наприклад, коефіцієнт трансформації, який характеризує ефективність теплового насоса 3 позицій Першого закону термодинаміки, надає односторонню характеристику. Він враховує сумарний вплив температур низькопотенційного джерела і споживача енергії та термодинамічної досконалості його циклу на ефективність трансформації енергії. Коефіцієнт трансформації не може сам по собі оцінити роздільно необоротності того чи іншого реального процесу в установці. Більше того, в окремих випадках цей параметр може дезорієнтувати дослідника

Кількісне оцінювання можливості реалізувати той чи інший процес в теплоенергетиці можливе із застосуванням положень Другого закону термодинаміки, зокрема, на основі ексергетичного аналізу [4]. Існує ряд термінів і пояснень поняття ексергії. 3. Рант, який і ввів цей термін, запропонував таке визначення ексергії - це $\epsilon$ частина енергії, яка може бути повністю перетворена в інші види енергії [5]. Методи ексергетичного аналізу в найбільшій мірі розроблено та апробовано в промисловій теплоенергетиці [1]. Разом з тим, в останній час з'явився інтерес до використання цих методів у сфері теплозабезпечення будівель [5], у системах керування об' єктами теплоенергетики [6], а також для діагностування цих об'єктів [7].

Метою роботи є підвищення ефективності математичного моделювання об'єктів та систем теплоенергетики на основі методів термодинамічного аналізу, а саме сумісного застосування Першого та Другого законів термодинаміки, а також ïх поєднання із економічним та екологічним оцінюванням.

\section{2. Методологія.}

На основі огляду сучасних методів прикладної термодинаміки обгрунтовано доцільність використання в моделюванні обєктів теплоенергетики понять ексергія «палива», ексергія «продукту», «деструкція ексергії» [3, 8].

Комплексний ексергетичний, економічний та екологічний (на основі оцінювання життєвого циклу) аналіз запропоновано реалізувати на основі алгебраїчного підходу із використанням методу питомої ексергетичної вартості та негативного впливу на довкілля (SPECO-метод) [3, 7]. Це обгрунтовано тим, що алгебраїчні методи (або методи ексергоекономічного та ексергоприродничого обліку) не ма- 
ють обмежень щодо типу і складності системи, їх можна ефективно застосовувати на стадії створення й оптимізації нової або модернізації наявної системи.

\section{3. Результати досліджень.}

Для прикладу було проведено математичне моделювання системи теплозабезпечення будинку з розрахунку сумарних за опалювальний період (для позначення використано верхній індекс year) значень деструкції ексергії $E_{D, k}^{\text {year }}$ в елементах теплонасосоної установки (ТНУ) типу «повітря-вода», піковому нагрівнику та опалювальному приладі. Показано, що найбільша сезонна деструкція ексергії характерна для ТНУ і становить 5254 кВт·год, а найменша - для пікового нагрівника і дорівнює 390 кВт·год. Сумарна за опалювальний період деструкція ексергії в опалювальному приладі становить 1514 кВт·год, тобто менше ніж у ТНУ на $72 \%$. Щодо ТНУ, то сумарні за опалювальний період значення деструкції ексергії становлять відповідно: у компресорі - 1752 кВт·год, у дросельному вентилі 1632 кВт·год, у випарнику - 1144 кВт·год, у конденсаторі - 726 кВт·год. Порівняно 3 компресором та дросельним вентилем деструкція ексергії у випарнику та конденсаторі є на $30 \ldots 65 \%$ меншою.

Результати ексергоекономічного та ексергоприродничого оцінювання системи теплозабезпечення будинку на базі ТНУ показали, що саме ТНУ характеризується не тільки найбільшою деструкцією ексергії, але і найвищими сумарними економічними затратами та сумарним впливом на довкілля.

У зв'язку з цим, в роботі запропоновано більш детально проаналізувати можливості змінювання характеристик цього елемента системи за допомогою методології поглибленого ексергетичного аналізу [8]. Проте, на відміну від наявних у літературних джерелах результатів такого аналізу, де розглянуто тільки один режим системи, у роботі запропоновано динамічний метод аналізу з подальшим обчисленням сезонних значень відповідних характеристик ексергетичного аналізу.

Результати першої ітерації ексергетичного, ексергоекономічного та ексергоприродничого оцінювання свідчать про те, що для одночасного зниження деструкції ексергії, загальної вартості $Z_{H P}^{\text {year }}+C_{D, H P}^{\text {year }}$ та впливу на довкілля $Y_{H P}^{\text {year }}+B_{D, H P}^{\text {year }}$ ТНУ у складі системи теплозабезпечення будівель необхідно підвищити термодинамічну ефективність випарника знижуючи температурний напір у ньому. Як показав аналіз, сумарні витрати у ТНУ $Z_{H P}^{\text {year }}+C_{D, H P}^{\text {year }}$ обумовлені переважно його капітальними затратами, витратами на обслуговування і ремонт $Z_{H P}^{\text {year }}$, i їх можна суттєво зменшити за допомогою зниження термодинамічної ефективності компресора. Крім того, як показали результати поглибленого ексергоекономічного аналізу, певну частину затрат у компресор $Z_{C M}^{\text {year }}$ можна зменшити за рахунок підвищення термодинамічної ефективності випарника та конденсатора. Тому запропоновано зменшити температурний напір у конденсаторі, що, згідно з отриманими результатами аналізу, з одного боку зменшить деструкцію ексергії у ТНУ та іï негативний вплив на довкілля, а з другого - частково знизить капітальні затрати, витрати на обслуговування і ремонт у компресор $Z_{C M}^{\text {year }}$, а отже, i у ТНУ $Z_{H P}^{\text {year }}$.

На основі аналізу системи з позицій сумісного врахування Першого та Другого законів термодинаміки зроблено висновок, що певну частину деструкції ексергії у ТНУ може бути знижено за рахунок удосконалення інших елементів системи теп- 
XX Міжнародний симпозіум «Методи дискретних особливостей в задачах математичної фізики/Discrete Singularities Methods in Mathematical Physics»,

\section{МДОЗМФ/DSMМРh-2021}

лозабезпечення (піковий нагрівник, опалювальний прилад) або структурних змін. 3 огляду на це, обгрунтовуючи параметри й тип системи відповідно до прийнятих критеріїв запропоновано проаналізувати такі варіанти: 1) - зниження температурного напору у випарнику та конденсаторі ТНУ, 2) - заміна опалювальних приладів, що працюють за температурним графіком $70{ }^{\circ} \mathrm{C} / 50{ }^{\circ} \mathrm{C}$, на низькотемпературні 3 температурним графіком $60^{\circ} \mathrm{C} / 40{ }^{\circ} \mathrm{C}$, збільшуючи їх площу нагрівання; 3) - підвищення приведеного опору теплопередачі огороджувальної оболонки будинку. На рис. 1 наведено значення цільових функцій обгрунтування параметрів системи теплозабезпечення будівлі на базі ТНУ для розглянутих варіантів.

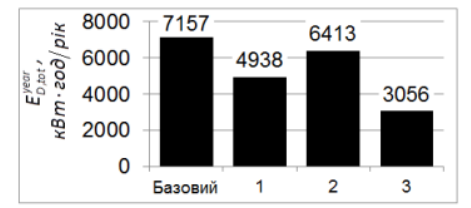

a)

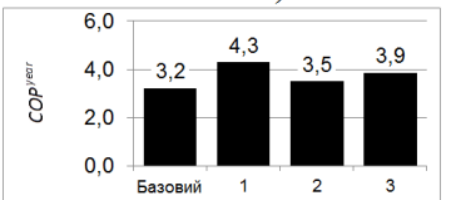

Г)

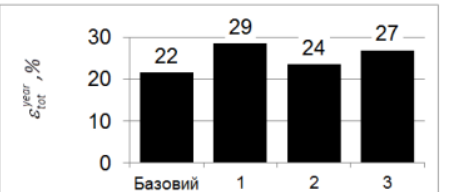

б)

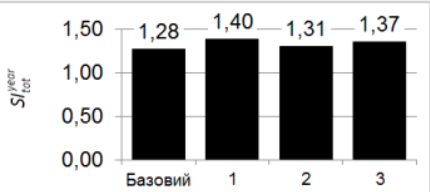

B)

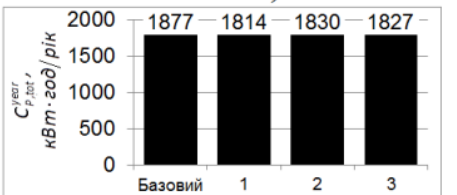

д)

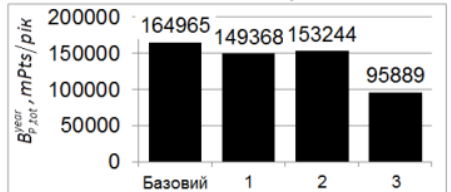

e)

Рис. 1. Змінювання річних значень деструкції ексергії (а), ексергетичного ККД (б), коефіцієнта трансформації ТНУ (в), індекса сталості (г), ексергетичної вартості «продукту» (д) та негативного впливу на довкілля «продукту» (е) системи теплозабезпечення будинку на базі ТНУ

Отже, 3 наведених на рис. 1 даних видно, що для вибраної групи критеріїв найкращими $є$ варіанти 1 та 3. Річна деструкція ексергії варіанта $3 €$ найнижчою, дорівнює 3056 Євро/рік і у 2,3, 1,6 та 2,1 рази нижча порівняно з базовим та варіантами 1 і 2 відповідно. Річний ексергетичний ККД варіанта 1 найвищий і становить $29 \%$, а базового та варіанта 2 і 3 відповідно 22, 24 і 27 \%. Річний індекс сталості для базового варіанта, 1,2 та 3 рівні відповідно 1,28, 1,40, 1,31 та 1,37, тобто за цим параметром варіант 1 також $є$ найкращим. Варіант 1 характеризується також найвищим значенням річного коефіцієнта трансформації, який дорівнює 4,3. Для базового та варіантів 2 і 3 цей параметр становить відповідно 3,2, 3,5 та 3,9. Річна ексергетична вартість «продукту» системи для варіанта $1 €$ на 3,3, 0,9 та 0,7 \% меншою порівняно 3 базовим та варіантами 2 і 3. Річний негативний вплив на довкілля «продукту» системи для варіанта $3 є$ на 42, 36 та 37 \% менший порівняно відповідно $з$ базовим та варіантами 1 та 2.

Таким чином, за допомогою методів ексергетичного аналізу після трьох ітерацій вдалося досягнути одночасного покращення ексергетичних, економічних та екологічних характеристик системи теплозабезпечення будинку з використанням ТНУ. Саме використання методів ексергетичного, ексергоекономічного та ексергоприродничого аналізу дало змогу чітко визначити місце, значення, джерела, вартість і вплив на довкілля термодинамічної неефективності у цій системи.

Стаття підготовлена в рамках виконання проекту «Розроблення технікотехнологічних схем та систем керування теплозабезпечення населених пунктів на основі термодинамічних підходів» (номер держреєстрації НДР 0120U102168). 


\section{ЛІТЕРАТУРА}

1. Frangopoulos Ch.A., Sakalis G.N., Tzortzis G.J. Intertemporal and dynamic optimization of synthesis, design and operation of energy systems. The 4th International Conference on Contemporary Problems of Thermal Engineering (CPOTE-2016). September, 14-16, 2016. Gliwice - Katowice, Silesia, 2016. P. 3-28.

2. Клер А.М., Деканова Н.П., Щеголева Т.П. и др. Методы оптимизации сложных теплоэнергетических установок. Новосибирск: ВО «Наука», 1993. 116 с.

3. Bejan A., Tsatsaronis G., Moran M. Thermal Design and Optimization. New York: Wiley, 1996. $542 \mathrm{p}$.

4. Sciubba E., Wall G. A brief Commented History of Exergy From the Beginnings to 2004. International Journal of Thermodynamics. 2007. Vol. 10, No. 1. P. 1-26.

5. Hepbasli A. Low exergy heating and cooling systems for sustainable buildings and societies. Renewable and Sustainable Energy Reviews. 2012. V. 16(1). P. 73-104.

6. Sangi R., Müller D. Application of the second law of thermodynamics to control: A review. Energy. 2019. Vol. 174. P. 938-953.

7. Wang L., Fu P., Wang N., Morosuk T., Yang Y., Tsatsaronis G. Malfunction diagnosis of thermal power plants based on advanced exergy analysis: The case with multiple malfunctions occurring simultaneously. Energy Conversion and Management. 2017. Vol. 148. P. 1453-1467.

8. Morosuk T., Tsatsaronis G., Advanced exergy-based methods used to understand and improve energy-conversion systems. Energy. 2019; 169: 238-46.

\section{Моделирование объектов теплоэнергетики методами}

Надійшла 20.05.2021.

\section{термодинамического анализа}

${ }^{1}$ В.А. Волощук, ${ }^{2}$ Е.И. Никифорович

${ }^{1}$ НТУУ "Киевский политехнический институт имени Игоря Сикорского", Киев, Украина

E-mail:vl.volodya@gmail.com

${ }^{2}$ Институт гидромеханики НАН Украины, Киев, Украина

E-mail: eugnik@gmail.com

Наиболее распространенные подходы к исследованию объектов теплоэнергетики предусматривают многократную реализацию таких последовательных шагов расчета, как термодинамика, тепломассообмен, гидрогазодинамика, экономика и экология, и не в состоянии оценить и совместить экономические, экологические и термодинамические аспекты с самого начала анализа, выяснить не только внешние, но и внутренние, обусловленные термодинамической несовершенством элементов системы, факторы влияния на экономические и экологические характеристики. Методы моделирования, основанные на совместном использовании Первого и Второго законов термодинамики (методы энтропийного и эксергетического анализа), и их сочетание с экономической и экологической оценкой дают возможность определить, значение, причины, стоимость и негативное влияние на окружающую среду термодинамических потерь в процессах передачи и преобразования энергии. В работе предложено усовершенствование методов моделирования объектов теплоэнергетики с применением эксергетического анализа. Показано, что решение задач обоснования параметров и структуры объектов исследования путем объединения эксергетического, экономического и экологического методов оценивания существенно упрощается. Приведены примеры реализации такого моделирования.

Ключевые слова: моделирование, теплоэнергетический объект, эксергетический анализ. 